\title{
Convergence through Next Generation Cloud and Service Oriented Networks in the Indian Scenario
}

\author{
Parag Pruthi ${ }^{1}$, Ashutosh Dutta ${ }^{2}$, Niranth Amogh ${ }^{3}$ \\ and Ritesh Kumar Kalle ${ }^{4}$ \\ ${ }^{1}$ NIKSUN USA, email: parag@niksun.com \\ ${ }^{2}$ AT\&T USA, email: ad5939@att.com \\ ${ }^{3}$ Huawei R\&D India, email: namogh@huawei.com \\ ${ }^{4}$ NEC India, email: ritesh.kumar@necindia.com
}

Received July 2013; Accepted August 2013

\begin{abstract}
Cloud and Service Oriented Networks are integral part of the convergence strategy laid out by Government of India through the National Telecom Policy 2012. This paper describes the key requirements for converged cloud and services infrastructure framework and architecture that have impact on standardization. The requirements not only include perspectives of Indian challenges for the infrastructure but also include the challenges imposed by innovative applications and services that are to be delivered through the Next Generation of Cloud and Service Oriented Networks.
\end{abstract}

Keywords: Cloud, Service Oriented Networks, Applications, Service Infrastructure, Convergence, Service Delivery, Standardization, Context Awareness, Self Organization, Emergency Services.

\section{Introduction}

Service oriented network principles provide the necessary foundation for delivering the vision of convergence of service delivery for multiple market segments. Cloud computing is adopted to build cost and energy efficient

Journal of ICT Standardization, Vol. 1, 187-204.

doi:10.13052/jicts2245-800X.12a5

(C) 2013 River Publishers. All rights reserved. 


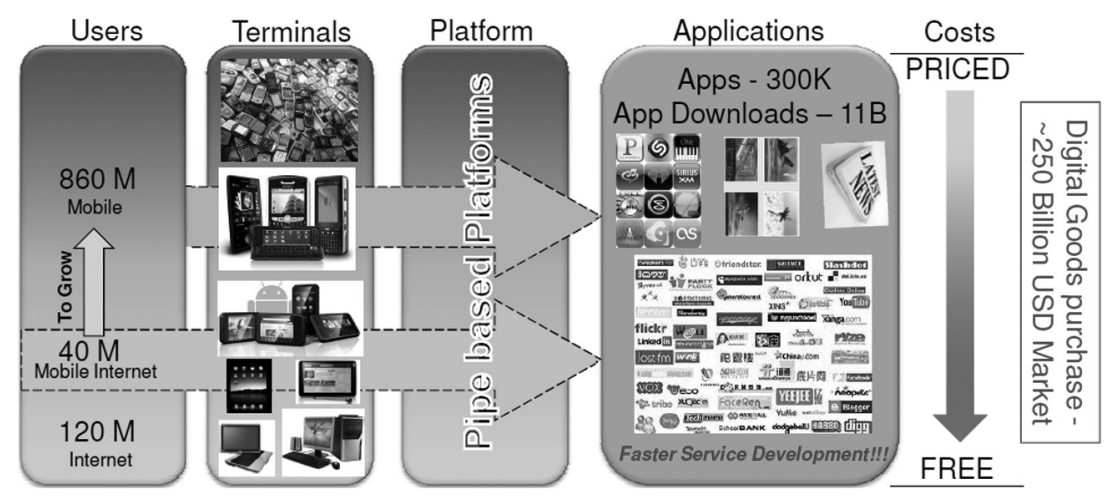

Figure 1 Indian market scenario.

service delivery mechanisms. Most recently the Indian government has laid out its objectives and missions in the area of convergence and cloud services through the NTP (National Telecom Policy) 2012 and the Draft National Policy on Information Technology 2011. Cloud \& Service Oriented Networks are intended to support multimodal communication environments where information can be communicated through a variety of terminal devices, network access technologies, and underlying infrastructures. The information may be presented in real-time (e.g., interactive voice) or time-shifted (e.g., voice mail), in its original format (e.g., analog speech) or transformed (e.g., file attachment). The information can be delivered by the network to a location, a device, or a person, reflecting personal preferences and mobility options.

Figure 1 shows that the number of mobile subscribers in India is increasing at a high rate and is only next to China. Even the mobile Internet growth is increasing steadily owing to the proliferation of end user devices which deliver various levels of user experience. The application space has been struck by various innovations quite rapidly and is now being delivered by Over The Top (OTT) providers using the telecom network. A study from TellLabs suggest that operators or telecom service providers worldwide especially in developing countries need to transform their networks and business models to be aligned to Cloud and Service Oriented Networks in the next 3 to 5 years.

\section{Requirements and Gaps for India}

Service providers are highly interested in leveraging existing networks and infrastructure to increase the value of those networks by enhancing their 


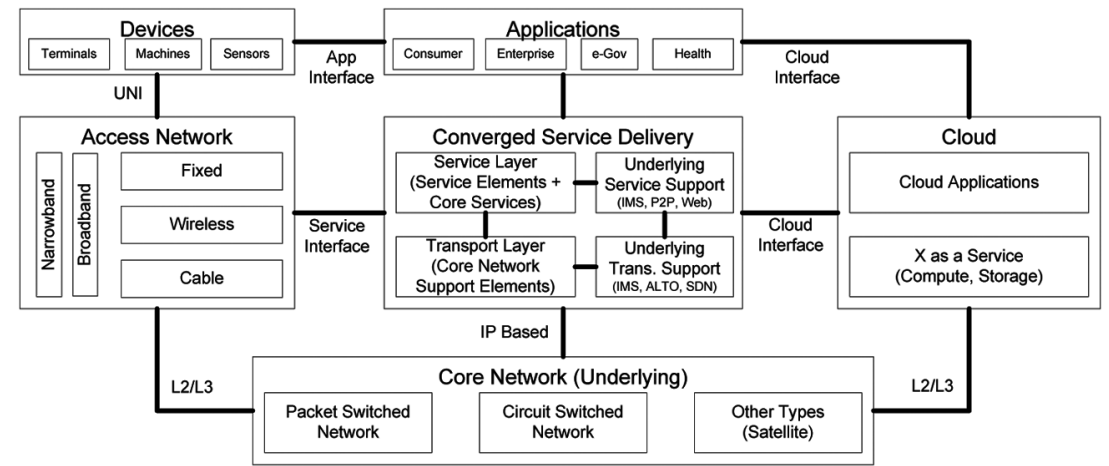

Figure 2 Convergence framework for cloud and service oriented networks.

ability to offer customers "seamless" delivery of applications independent of any access or transport technology. This framework provides a common architecture and set of service interfaces to address this basic goal. Adhering to this architecture and to the services and service models set forth, provides a common framework for delivering services, irrespective of the network context. Regulatory requirements may affect any telecommunications services provided. These requirements can be classified broadly in a framework as shown in the Figure 2.

A service oriented network enables the new providers to offer value added services while using the existing underlying services. It shows a multi-tiered architecture. At the lowest layer there are multiple types of networks providing a layer of network convergence. On the top of network layer there is common service platform layer. This layer consists of services as offered by IMS (IP Multimedia Services) and OMA (Open Mobile Alliances). Current operators and new service providers offer new variety of services using the third party APIs and protocols. CSeON WG will define these APIs and protocols that allow the existing service providers and the new ones to offer a variety of services.

Figure 3 shows how $\mathrm{CSeON}$ domain takes the best of three domains such as IMS (IP Multimedia Subsystem), Cloud/SOA (Service Oriented Architecture) and WEB 2.0. While IMS is suitable for Telco, WEB 2.0 is most suited for Web domain. On the other hand, Cloud/SOA is most suited for IT domain.

\subsection{Convergence}

The CSeON target architecture must not only separate services from transport, but must enable efficient interworking between applications to support 


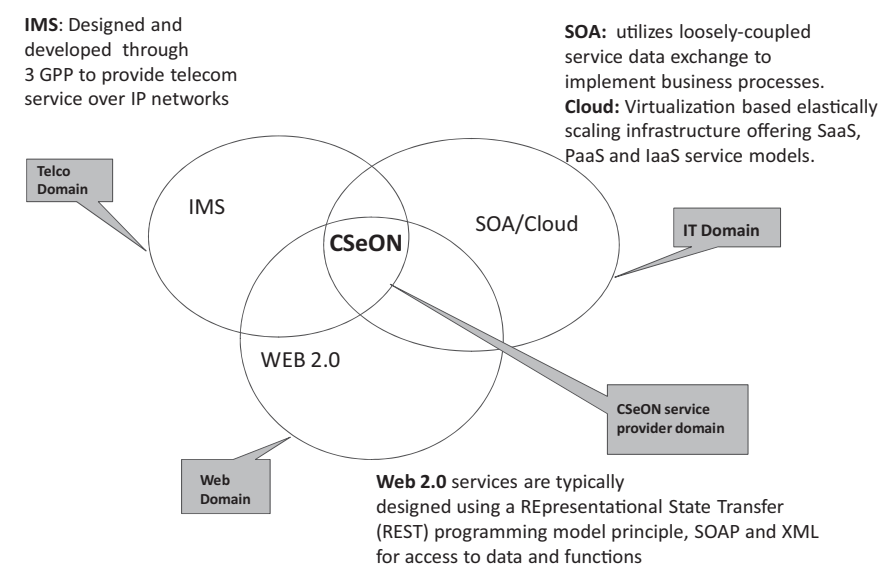

Figure 3 Cloud and service oriented networks domain.

innovative converged services. Many of today's services are verticallyintegrated which inhibits integration with other applications. This interworking can add value to the existing as well as new services by integrating them into the larger convergence of media and access modes, allowing service providers to roll out the kind of customized and convenient advanced services that segments of their markets are already asking for today. By putting the disparate parts of the communications puzzle together (such as wireline and wireless services, switched and IP networks, voice and other media, and access modes of all types), service providers have the flexibility to create the right combinations of services for their markets and deploy them to the benefit of end customers.

To make the transition to a fully converged CSeON network, service providers need a standards-based, converged service-enabled network architecture that is ready and able to deliver value-added services. To fulfill these needs, the resulting architecture should support:

- Open, standards-based interfaces allowing "plug-and-play" integration of any number of applications.

- Full convergence of services over a number of access modes - blending instant messaging with unified communications and VoIP, for example.

\subsection{Rural India}

As per the Census of India,approximately $70 \%$ of country's population lives in Rural India. There are almost 600,000+ villages in the country with 1000 
people per village and per capita income of Rs. 20 to 25 per day. The rural tele-density in India is $40.07 \%$ as compared to urban tele-density of $148.46 \%$, as on January 2013 . The country's tele-density is $73.07 \%$ compared to world's tele-density of $96 \%$.

The people in rural India, needs connectivity in order to be fully connected to the progressing world in order to make it a truly symbiotic society. For telecom operators, it is thousands of customers subscribing every day while for equipment vendors it brings a unique challenge to develop new solutions that provide the access to these communities.

Following are the requirements specific to rural India,

- Low population density

- Low income levels

- Lower literacy levels

- Sparsely populated and geographically dispersed areas

So, any business model prepared for rural area should be:

- Affordable (cheaper)

- Reliable

- Rich in Contents (like Value Added Services specific to the needs of people working in agricultural domain)

- Available in local language

- Self sustainable

- Replicable

- Scalable

- Easier and faster to deploy

- Deploy alternate source of Energy like Solar power

- Low maintenance and Support Cost

Low maintenance network equipment suitable for rural environment considering the following factors,

- Lack of continuous power supply

- Lack of high available infrastructure

- Harsh environmental conditions

- Low literacy level

\subsection{Deliver Secure Applications and Services}

Security is one of the most essential enablers and differentiators in CSeON. Identifying services and the users, authorizing the service to access specific 


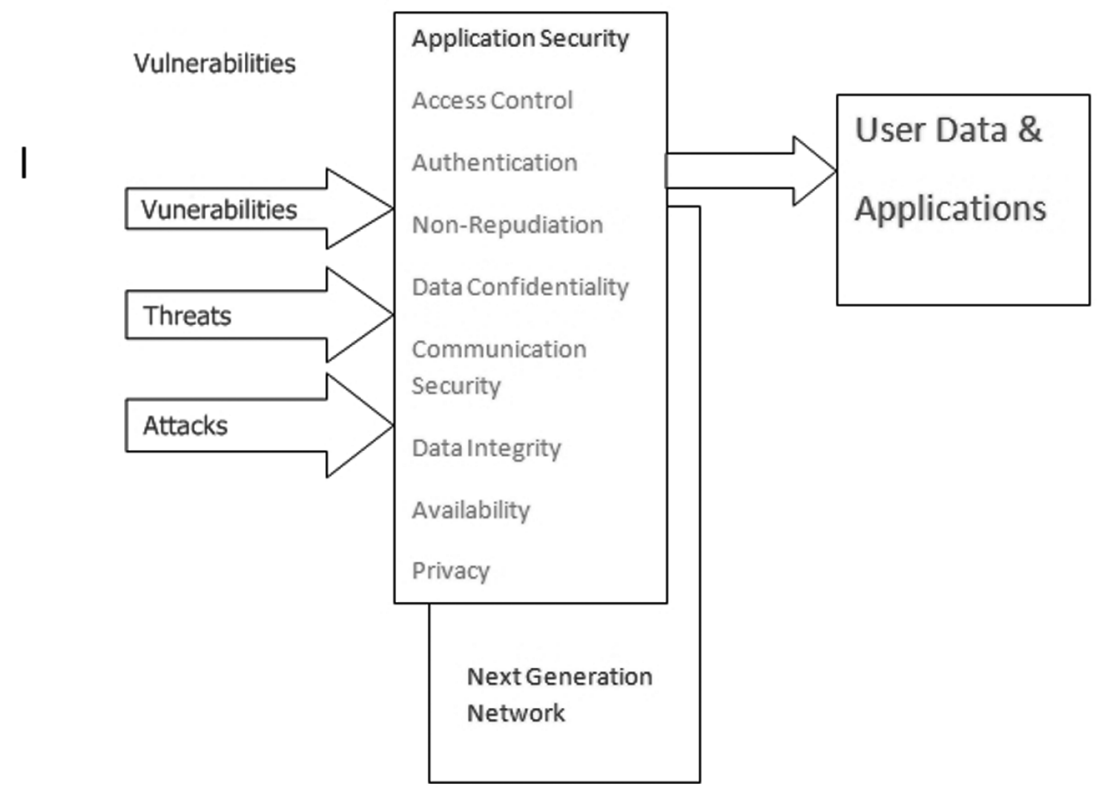

Figure 4 Eight security enablers.

content based on one's access rights and authenticating the service to use appropriate resources are required. The essential enablers are shown in Figure 4.

- Access Control: Enabling access authority to control the access of the resources, protecting of copy rights. Implement the policy to describe how to secure access a data resource.

- Authentication: Confirming the identity of the person, tracing its origins and ensure that the application is the same as it intends to. Focus is on authentication for both device and end users and how far authentication goes: User to phone (for highly secure environments); User Agent to IMS; IMS to User Agent; User to IP-CAN; IP-CAN to User; User Agent to User Agent; Cross domain authentication; Authentication of Signaling messages; Authentication of media packets; Authentication of messages that traverse PSTN <-> Packet Networks through Signaling/Media gateways.

- Non-repudiation: Techniques like Digital signature should be used not only to ensure that a message or document has been electronically signed by the person. Ensure that a person cannot later deny that they furnished the signature. 


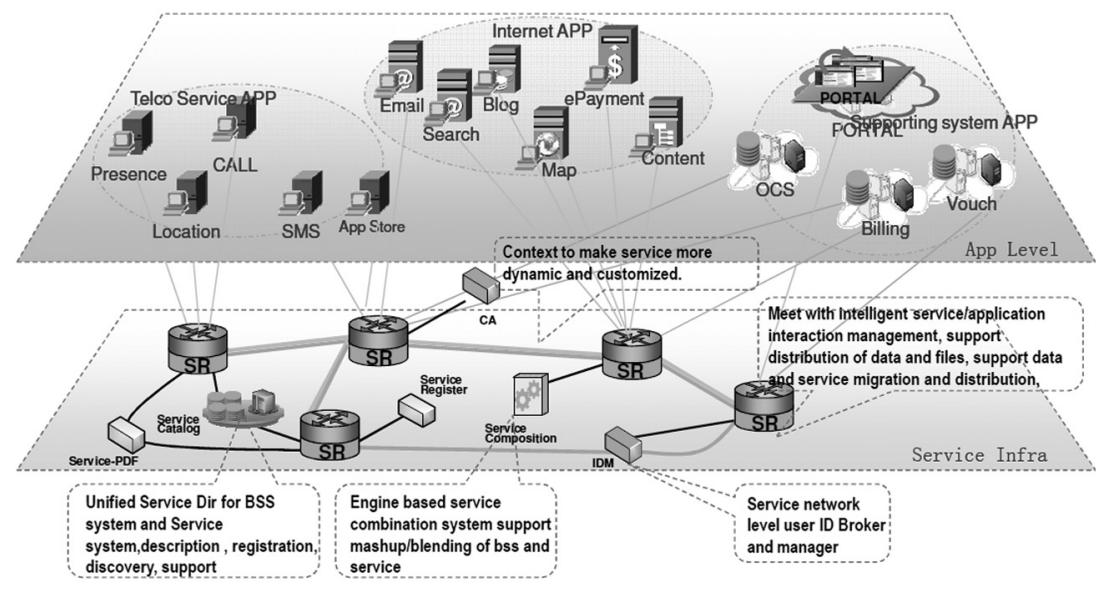

Figure 5 Service cloud.

- Data confidentiality: Provide infrastructure for encryption and password authentication.

- Communication security: Platform to deny unauthorized access of data and resources. Security refers to the need to ensure that communications between endpoints cannot be unlawfully intercepted or redirected.

- Data Integrity: Assurance that data is consistent certified and can be reconciled.

- Availability: Resources and data need to be available when required.

- Privacy: CSeON can be combined with identity authentication (e.g. RFID can be used).

\subsection{Cloud Services}

$\mathrm{CSeON}$ shall be able to leverage all the service models of Cloud like IaaS, SaaS, PaaS(as described by NIST) to allow an operator to provide and operate a cost efficient $\mathrm{CSeON}$. CSeON should be able to provide a PaaS layer for $\mathrm{CSeON}$ services. Shall enable a service eco-system by combining services from different networks and enabling stakeholders to develop innovative applications and deliver seamlessly over any network. For example, a service infrastructure consisting of service processing nodes which enables seamless integration and interaction of services from telecom and Internet as shown in the Figure 5. 
- Support SaaS model:CSeON shall be able to deliver services like mashup applications as Software as a Service based on pay per use model.

- Compute as a Service:CSeON shall be able to utilize the Public/Private cloud for processing complex service tasks such as personalization

- Storage as a Service:CSeON shall be able to utilize the public/private storage cloud on demand to meet the high scale data storage and also be able to support the real-time and non-real time data/content access requirements. This public storage requirement is only for non-sensitive data/content. All user-related information should be stored in a private cloud operated upon by the service provider.

\subsection{Applications and Services}

Indian telecommunication deployment is unique in terms of geography and user density. Currently the wireless subscribers (CDMA, GSM/GPRS) dominate the subscriber base with close to 900 Million subscribers in 23 telecom circles and rest are fixed line subscribers (PSTN, DSL) with a base of around 30 Million. While the wireless space is dominated by Private Telecom Service Providers (TSPs), the wired telecom is still under the domination of Public Sector Undertaking (PSU) telecom companies. Though the urban tele-density has reached close to 160 percent, the rural tele-density is still lagging behind at 40 percent penetration. Indian telecom market has evolved over time and consists of-multiple operators, multi-vendor equipments, multi-technology (GSM, CDMA, 3G, LTE) equipments, wired-line and long distance networks.

Since all these technologies are governed by separate specifications, it is important to find technology solutions and standardize the interconnectivity for various applications and services which will be offered through a converged services framework. CSeON will enable some of the following services through the converged services framework:

\subsubsection{Emergency Telecom Services}

Since emergency is closely associated with the national security issues, appropriate regulatory requirements and Government policies are to be considered in this regard. The following key India specific requirements are envisioned:

- Numbering Plan: All the major categories of emergency services like Police, Fire, Ambulance, Hospital Related, Emergency Information Services, Emergency Disaster Management Services, Police Related Services should be available through a single number. Thus, for standardizing 
the single number emergency service, the numbering codes need to be defined.

- Location Tracking and Caller Identification Issues: Indian operators have currently not installed any form of mobile location tracking systems. DoT has set the deadline of year 2014 to install such a mobile location tracking system that is much more precise than the current system that provides the Cell ID of the subscriber. Centralized database of numbers for tracking handsets across all operators with confidentiality. Low GPS penetration in Indian subscribers implies that the solution needs to depend on triangulation and other similar mechanisms supported by the network infrastructure. Real-time transfer of caller identification \& location information is needed. Spare capacity in public networks needs to be reserved for handling of emergency traffic,location tracking for SMS, data calls, SIM-less emergency calls, etc.

- Public Service Access Points (PSAP): The PSAP should be accessible for the single number and should be reachable over all telephony networks within the country with dedicated resources provisioned. Both centralized and distributed architectures should be analyzed with controls provided to independent authority.

- Local Language Support and Social Inclusion: Indian language diversity is a big challenge to provide good reachability of emergency services. These services should be available in local languages. As part of the social inclusion, the emergency services should be made available to persons with speech and hearing impairments with non-voice accessibility such as text and gesture based solution.

- National Security Implications: The national emergency services infrastructure should be protected from various threats such as physical and software related attacks (virus, malware, DoS, etc), network failures (power failure, infrastructure damage, etc), congestion due to network overload during disasters and hoax calls.

\subsubsection{E-Health Services}

As an initial effort to connect the medical network to the end users, e-Health services should be effectively deployed by CSeON. e-Health services should improve the accessibility of medical services to rural sector in particular. Gradually the government should be able to introduce e-Health applications like electronic health records, almost real-time automated health monitoring and emergency services, diet control and health tips. 


\subsubsection{E-Governance Services}

In the area of e-Governance the applications aiding communication like Government to Citizen (G2C), Government to Business (G2B), Government to Governments (G2G), Government to Employees (G2E) and Citizen to Government $(\mathrm{C} 2 \mathrm{G})$ should be effectively deployed by $\mathrm{CSeON}$ by harnessing existing citizen identity projects like Aadhaar.

\section{Standardization Approach}

The GISFI Cloud \& Service Oriented Network (CSeON) Standardization Working Group is driven by the business needs of the Indian market. The goal is to produce CSeON Standards, consistent with the unique Indian regularity, business and infrastructure (urban as well as rural India) requirements. The GISFI CSeON Working Group will focus on providing a phased businessdriven action plan for achieving implementable and interoperable CSeON standards.

Following is the list of other standards forums that could collaborate closely with the GISFI CSeON WG or provide ongoing liaisons. These include:

- Ministry of Communication and Information Technology (MIT)

- Cellular Operators Association of India (COAI)

- ITU-T: SG13, including the Focus Group on Next Generation Networks (FGNGN)

- 3rd Generation Partnership Project (3GPP)

- European Telecommunications Standards Institute (ETSI) TISPAN

- IEEE P1903 (NGSON) project

- 3rd Generation Partnership Project \#2 (3GPP2)

- GISFI Technical Committees

\subsection{Candidate Areas for Standardization in CSeON}

- QoS: End to End QoS for composed services/applications in a multioperator environment.

- Service Composition: Composition of services/applications in a multioperator environment,especially rapid application adaptation for semiurban and rural applications.

- Self Organization: Self organization of service operations applicable in a multi-operator environment. 
- Content Delivery: Content delivery in a multi-operator environment. Efficient mechanisms to reach semi-urban and rural users.

- Context Awareness: Adaptation of application based on contexts of users, networks, device and services.

- Identity Management: Handling multi-identity in the form of Global ID across multi-operator environment.

- Cloud security monitoring: Monitoring the attack vectors to avoid any disruption of cloud services

\section{Cloud and Service Oriented Networks WG Charter}

The main objective of GISFI CSeON WG is to develop phase-wise standards and implement through suggestive Generic Requirements (GRs) from Government of India. The CSeON WG has focussed its tasks and activities as follows:

- Analysis and Requirements: Gather $\mathrm{CSeON}$ requirements and establish liaison with Indian stakeholders. Publish technical reports in this subject matter.

- Standardization: Develop standards based on the gaps and provide a platform to recognize these Indian requirements and standards in the international standards community. Publish standards in India and also make contributions to international standard bodies.

- Implementation \& Deployment: Participate with all Indian stakeholders to implement the standards and provide consultation to the Indian government on the deployment models and regulations for a establishing and operating a sustainable business.

\subsection{Technical Reports}

As part of the analysis activities the following technical reports will be published by the CSeON WG:

- CSeON Requirements and Framework: This technical report provides detailed requirements for Cloud and Service Oriented Networks and in particular large focus is laid on Indian requirements.

- Business Models for CSeON: This technical report focuses on eliciting the business scenarios and challenges which focus on establishing and operating a long term sustainable business based on CSeON. 
- Information Management for CSeON: This technical report focuses on technical challenges involved in managing large scale information operated upon by the $\mathrm{CSeON}$ providers. It also proposes method to migrate legacy information system to CSeON model.

- Carrier Grade Cloud Computing: This technical report provides new and emerging architectures to provide high performance, cost and energy efficient compute, data, platform and software services.

- Emergency Telecom Services: This technical report provides technical challenges and standards involved in providing emergency services in Indian context.

\subsection{Collaborations}

Collaboration is key to building a sustainable environment for innovative standardization. It is important to work together in an ecosystem where similar problems are being solved and fit together in the overall convergence vision. $\mathrm{CSeON}$ WG has taken up the collaboration activities with the following groups in other standardization bodies.

- IEEE P1903 (NGSON): This group focuses on developing standards in the emerging area of Next Generation Service Overlay Networks (NGSON). CSeON WG has successfully setup liaison with this SDO.

- IETF CCNS: This group focuses on developing RFCs for Cloud Computing and Network Services area. A liaison is initiated with IETF Internet Architecture Board (IAB) in this area.

- TEC:Telecommunication Engineering Centre is the Indian government body responsible for investigating standards and researching new products and services. A liaison is initiated with Information Technology (I) division and the Next Generation Networks (NGN) division.

- ATIS CSF:Cloud Services Forum focuses on developing framework for Cloud Services. A liaison is intended with this group.

- ETSI NFV: ETSI Network Function Virtualization group focuses on virtualizing the network functions in next generation networks including both wireline and wireless networks. Efforts are underway to set up collaboration between NFV and IEEE NGSON.

\section{Conclusion}

The diverse Indian requirements aimed at convergence of networks, services and devices are only possible through standards based interoperable cloud and 
service oriented networks infrastructure. A strategic convergence framework is required to enable diverse business needs as shown in Figure 2. This convergence framework will be a collaborative effort which involves combining standards from various industry bodies like GISFI, TEC, IEEE, ATIS, ETSI, etc.The goal of GISFI CSeON working group is to collaborate and produce CSeON Standards, consistent with the unique Indian regularity, business and infrastructure (urban as well as rural India) requirements.

\section{References}

[1] Government of India, National Telecom Policy - 2012, May 2012, http:// www.dot.gov.in/ntp/NTP-06.06.2012-final.pdf

[2] Government of India, Dept. of Electronics and Information Technology, National Policy on Information Technology (NPIT 2011), Oct 2011, http:// deity.gov. in/sites/upload_files/dit/files/National_Policy_on_Information_Technology_07102011(1) .pdf

[3] Parag Pruthi, AshutoshDutta, Niranth Amogh, CSeON Requirements and Framework, Draft, Sep 2012, http://gisfi.org/wg_documents/GISFI_CSeON_201209310.doc

[4] Anand R Prasad, Business models for CSeON, Jun 2011, http:// gisfi.org/wg _documents/GISFI_SeON_20110675.doc

[5] ATIS Cloud Services Forum (CSF), 2009, http://www.atis.org/cloud/index.asp

[6] IETF NVO3 (Network Virtualization Overlays), http://datatracker.ietf.org/wg/nvo3/ charter/

[7] IETF SDNRG (Software Defined Networking Research Group), http://trac. tools.ietf.org/group/irtf/trac/wiki/sdnrg

[8] SCIM (System for Cross-domain Identity Management), http://datatracker.ietf. org/wg/scim/charter/

[9] IEEE NGSON Whitepaper, 2008, http://grouper.ieee.org/groups/ngson/P1903_2008_0026White_Paper.pdf

[10] TellLabs Study, Feb 2011, http://www.tellabs.com/news/2011/index.cfm/nr/142.cfm

[11] TRAI: Telecom Subscription Data, Jan 2013, http://www.trai.gov.in/ Write Read Data/WhatsNew/Documents/PR-TSD-Jan2013.pdf

[12] IAMAI: Internet and Mobile Association of India http://www.iamai.in/

[13] The NIST definition of Cloud Computing, 800-145, Sep 2011, http://www. nist.gov/manuscript-publication-search.cfm?pub_id=909616

[14] NIST Cloud Computing Reference Architecture, 500-292, Sep 2011, http://www. nist.gov/manuscript-publication-search.cfm?pub_id=909505

[15] Aadhar enabled Service Delivery, Feb 2012, http://uidai.gov.in/images/authDoc/ whitepaper_aadhaarenabledservice_delivery.pdf

[16] Guidelines on Security and Privacy in Public Cloud Computing, Dec 2011, http:// www.nist.gov/manuscript-publication-search.cfm?pub_id=909494

[17] The Indian Telecom Services Performance Indicators July - September 2012, http://www.trai.gov.in/WriteReadData/PIRReport/Documents/Indicator \%20 Reports \% 20-\% 20Sep_2012.pdf 
[18] National number plan http://www.dot.gov.in/numbering_plan/nnp2003.pdf

[19] COAI Response to DoT instruction to setup Location Based Services in mobile networks http://coai.in/docs/PressReleases/Press\%20Release\%20\%20Location\%20Based\%20Services\%20-\%2016-6-2011.pdf

[20] Draft Amendment to the Telecommunications (Emergency Call Service) Determination 2002 - blocking of SIM-less calls, Consultation Paper, ACMA, Australia, 2007. www.acma.gov.au

[21] Mobile Standards Association of India URL: http://www.msai.in/

[22] COAI input at ETS Workshop Organized by TRAI http://www.trai.gov.in/WriteReadData /Events/Presentation/PPT/201211050554241072138Shri\%20Vikram\%20Tiwathia\%20\%20Associate\%20Director\%20General,\%20COAI.pdf

[23] National Emergency Number Association Standards http://www.nena.org/?page= Standards

[24] Expectations of the deaf and hard of hearing communities http://www.911.gov/pdf/TDI11072006.pdf

[25] Crime and Criminal Tracking System, MHA, Govt. of India http://ncrb.nic.in/cctns.htm

[26] Instructions on verification of new mobile subscribers (Prepaid and Postpaid) http://www.dot.gov.in/as/2012/DOC181012.pdf

[27] Single number access for non emergency services. http://pib.nic.in/newsite/erelease .aspx? relid $=86571$

[28] Rural Urban Distribution of Population, Census of India 2011. Govt. of India. http:// censusindia.gov.in/2011-prov-results/paper2/data_files/india/Rural_Urban_2011.pdf

[29] ICT Facts and Figures 2013, ITU-T http://www.itu.int/en/ITU-D/Statistics/Documents/ facts/ICTFactsFigures2013.pdf 


\section{Biographies}

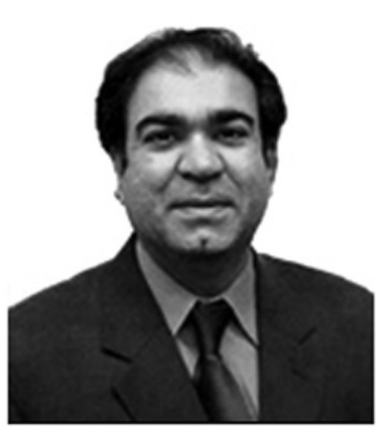

Dr. Pruthi brings over twenty-five years of expertise in the network security, wireless and applications analysis industry. Dr. Pruthi is the founder of NIKSUN which he has built from a startup to a highly successful global company leading the way in the cyber security, wireless and network monitoring markets.

Dr. Pruthi is widely recognized as the founding father of packet capture, stream to disk, bit vacuum, and other similar technologies which he brought to market in 1997 as

NetVCR. He is also widely accepted as one of the leading innovators in the field of cyber security. In 2001 he introduced the NetDetector as the only device in the world capable of multi gigabits per second line rate recording and simultaneous analysis, reconstruction and replay in order to discover the source of security incidents and identification of potential information leakage. This invention led to the creation and growth of the field of network forensics.

Recognized as one of the foremost experts in advanced cyber security technologies, Dr. Pruthi advises on cyber defense strategies with some of the highest levels of governments and enterprises around the world. $\mathrm{He}$ is a frequent speaker on cyber security issues, including keynotes to delegates from across 28 NATO nations, agencies, and strategic commands at the NATO Information Assurance Symposium 2010 and 2011.

Dr. Pruthi holds a Bachelor's degree in Electrical Engineering and a Master's in Computer Science from Stevens Institute of Technology. He also has a Doctorate in Telecommunications from The Royal Institute of Technology, Stockholm, Sweden, and his thesis, "An Application of Chaotic Maps to Packet Traffic Modeling," was the first to apply chaotic and fractal or self-similar systems to accurately model the seemingly erratic nature of network traffic.

Dr. Pruthi has received many honors, is interviewed frequently by news and media and asked to write various articles on a diverse set of topics. Notable were his interview with General Norman Schwarzkopf on Cyber Security which aired on CNBC and various other media outlets; cover story "Securing You Against The Unknown" in Silicon India Magazine's September 2011 issue; feature cover story in CIO Review's inaugural issue (April-May 2012); and a chapter on "Delivering a Long-Term Vision for Software" in the 
"Inside The Minds" series on "Growth Strategies For Software Companies." In 2012 SmartCEO magazine awarded Dr. Pruthi CEO of one of the BESTRUN COMPANIES in the Mid-Atlantic. In the same year, Network Products Guide named Dr. Pruthi Outstanding Leader of the Decade in the Information Technology Industry. In addition to a host of awards, his most cherished award is that from his peers at the IEEE who honored him with the IEEE Region 1 Award of Managerial Excellence for his Leadership, Entrepreneurship, and Cybersecurity Vision.

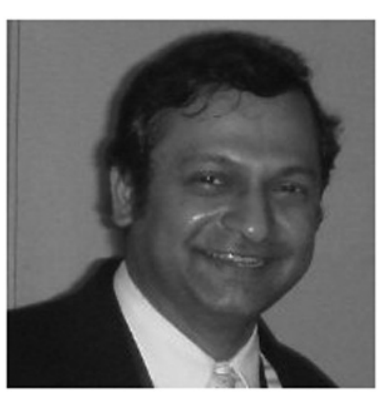

Dr. Ashutosh Dutta currently works as a Lead Member of Technical Staff at AT \& T. Earlier he worked as CTO Wireless at NIKSUN Innovation Center in Princeton, New Jersey where he is leading the research and development efforts in the area of $4 \mathrm{G}$ networks and service oriented networks. Most recently he worked as a senior scientist and project manager in Telcordia Technology's Applied Research, Piscataway, NJ for 13 years. Prior to joining Telcordia, Ashutosh was the Director of Central Research Facilities at Columbia University, from 1989 to 1997, and worked as a computer engineer with TATAs (Telco), India, from 1985 to 1987. Ashutosh's research interests include wireless Internet, multimedia signaling, mobility management, 4G networks, IMS (IP Multimedia Subsystems), VoIP and session control protocols. Ashutosh contributed to the research community by publishing his research results in journals, conferences, workshops and tutorials and serving as the general chair and technical program chair. He has published more than 80 conference, journal papers and Internet drafts, three book chapters, and has given tutorials in mobility management at various conferences. He was awarded 2009 IEEE MGA Leadership award and 2010 IEEE-USA professional leadership awards. Ashutosh has 19 issued US patents. Ashutosh Dutta is a senior member of the IEEE and the ACM. He obtained M. Phil. and Ph.D. in Electrical Engineering from Columbia University, New York. MS in Computer Science from NJIT and BS in EE from NIT Rourkela, India. 


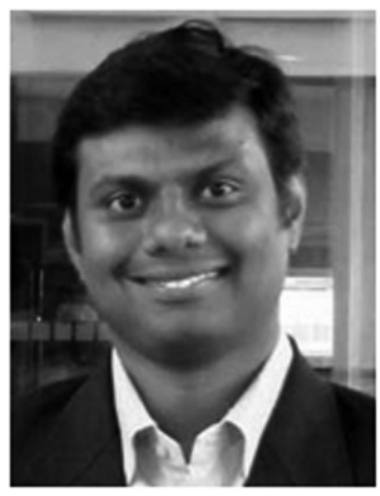

Mr. Niranth Amogh is the Sr. Lead Researcher at Huawei India R\&D Center at Bangalore and currently leads the NGSI (Next Generation Service Infrastructure) Technology Introduction Group and is responsible for Research and Standardization activities within the organization. His research interests include NGSON, SDN, Context Aware Computing, P2P, Cloud/Grid computing, Carrier Grade Cluster and Middleware and Telecom Network Management and he has filed several patents in his research. He is a member of various global telecom standardization bodies and technical societies, including a senior member of IEEE, a member of IEEE-SA, IEEE ComSoc, and ACM, as well as being principal contributor and project officer of the IEEE P1903 (NGSON) standards. Amogh is also the Vice-Chair for the Global ICT Standardization Forum for India (GISFI) Cloud \& Service Oriented Networks (CSeON) Working Group focused on standards development in India.

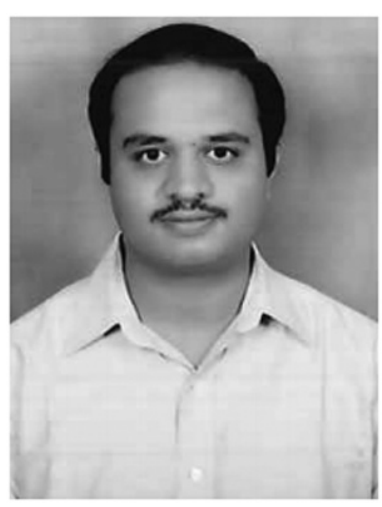

Dr. Ritesh Kumar is Research Engineer at NEC Mobile network Excellence Center (NMEC), Chennai, India. Prior to this, he was the Senior Scientific Officer and a full time PhD scholar in Wireless Networks Lab at IIITBangalore. He primarily works in related areas of modelling and performance analysis of Mobility, Power Saving and Quality of Service in Wireless networks, particularly LTE, WiMAX and Wi-Fi. His research was supported by Microsoft Corporation under the Microsoft Research India PhD Fellowship Award and the Department of Information Technology, Govt. of India. Ritesh has a graduate degree in Information Technology from IIITBangalore. He has applied several patents and has published extensively in peer reviewed International Journals and Conferences. 
